\title{
Trends in the use of care among people aged 65- 85 with cognitive impairment in the Netherlands
}

\author{
Mari Aaltonen ${ }^{1,2 \star}$, Jani Raitanen ${ }^{1,3}$, Hannie Comijs ${ }^{4}$ and Marjolein Broese van Groenou ${ }^{5}$ \\ ${ }^{1}$ Faculty of Social Sciences and Gerontology Research Center, University of Tampere, Tampere, Finland, \\ ${ }^{2}$ Institute for Advanced Social Research, University of Tampere, Tampere, Finland, ${ }^{3}$ UKK-Institute for \\ Health Promotion Research, Tampere, Finland, ${ }^{4}$ Department of Psychiatry, Amsterdam Public Health \\ Research Institute, VU University Medical Centre and GGZ inGeest, Amsterdam, The Netherlands and \\ ${ }^{5}$ Department of Sociology, Vrije Universiteit Amsterdam, Amsterdam, The Netherlands \\ ${ }^{*}$ Corresponding author. Email: mari.s.aaltonen@uta.fi
}

(Accepted 30 May 2018; first published online 20 July 2018)

\begin{abstract}
Observation of long-term trends within countries is needed to increase insight into how policy initiatives are reflected in the use of care over time in addition to individual determinants of care use. In the past decades, Dutch care policies have favoured homecare and reduced the availability of institutional care which extended the care responsibilities of formal and informal care-givers at home. This study investigates the changes in the use of informal and formal homecare, community services and residential care among cognitively impaired older adults over time in the Netherlands. In addition, of special interest here are the associations of the presence of a spouse, other family members or social network with care use, and the interdependency between the use of different types of care. The study employs the Longitudinal Aging Study Amsterdam (LASA) covering the years 1992-2012, analysed with generalised estimating equations. The data consisted of 1,022 observations gathered from 813 respondents aged $65-85$. The respondents were cognitively impaired according to the age- and education-standardised Mini-Mental State Examination score. The analyses took into account several individual determinants of care use. The use of informal care and residential care decreased while the use of formal homecare and community services remained the same. Simultaneously, the proportion of those who did not use the studied care types increased. The contribution of partners in informal care decreased. Informal care and formal homecare use increasingly became complementary services. The findings suggest that the decreases in informal care and residential care have not been replaced by other types of care, as reflected in the increased number of persons receiving no care. Care policies should not rely excessively on the availability of informal help and should guarantee adequate formal help, especially for those in high need.
\end{abstract}

Keywords: cognitive impairment; homecare services; informal care; residential care; trends, Longitudinal Aging Study Amsterdam (LASA) 


\section{Introduction}

Due to the ageing population, welfare states have explored new ways to organise health and social care in response to the increasing need for care and to achieve cost reductions. In several countries which have adopted universal health-care systems, this has led to the introduction of health and social care policies that emphasise living in the community as long as possible alongside a reduction in the availability of institutional long-term care services (Anttonen and Häikiö 2011, Connolly; Gillespie and O'Shea 2014; Da Roit 2012; Schön, Lagergren and Kåreholt 2016). The possible situation where a higher number of older people with health problems are living at home shifts the responsibility of daily care to informal care-givers, often family members such as a spouse or children, and also to formal homecare services.

We will study the trends in the use of care in the Netherlands in the years 19922012, and add to other trend studies on the use of care in the Netherlands (Alders, Comijs and Deeg 2016; Plaisier, Verbeek-Oudjik and de Klerk 2017; Swinkels et al. 2016), and other European countries (Johansson, Sundström and Hassing 2003; Pickard 2012), by focusing on a population that is largely dependent on others, that of cognitively impaired older adults.

In this study, we examine how the use of informal care and publicly funded services, i.e. formal homecare and community services, and the use of residential care has changed over time among those with cognitive impairment aged 65-85 in the Netherlands. The people with cognitive impairment are of interest because of their higher use of care compared with those without cognitive impairment (Vecchio et al. 2016; Zhu et al. 2013). People with cognitive impairment have disability problems in several areas compared with people with intact cognition (Dodge et al. 2005). This causes a loss of independence and increases the need for care provided by informal care-givers or formal health-care professionals and, at the more severe stage of the illness, a higher use of institutional care (Luppa et al. 2010; Matthews et al. 2016). Austerity measures may thus harm the cognitively impaired in particular. The availability of informal help is considered highly important in preventing or postponing institutionalisation (Luppa et al. 2008). As the presence of potential informal care-givers has become more important for the allocation of publicly provided formal and residential care over time, we study in particular how the use of care is associated with the presence of a spouse and family in the vicinity and the size of their social network.

The use of care is determined by individual characteristics, societal factors and the health-care system (Andersen and Newman 1973). Observation of long-term trends within countries are needed to increase insight into how policy initiatives are reflected in the use of care over time, in addition to individual determinants of care use such as health and social resources (Andersen and Newman 1973). Due to the fact that care networks are usually complex (Jacobs et al. 2016), and the policy initiatives may change the interdependency between the care types, the use of care is studied in different observational years to reveal the possible changes in substitution between the services among cognitively impaired older people. 


\section{Individual determinants of care use}

To investigate the trends in care use, the behavioural model of health service use was employed. The conceptual framework was introduced by Andersen and Newman (1973), and since then has been widely used and elaborated on by several authors (e.g. Alders, Comijs and Deeg 2016; Luppa et al. 2008; Pot et al. 2009). According to the model, the use of care relies on predisposing, enabling and need factors. Predisposing factors include demographic and social characteristics which exist prior to the onset of illness, such as age, gender and education. Enabling components represent conditions that make health service resources available to the individual and include factors such as income and family resources. Need factors consist of illness-related factors that are the immediate cause for the use of care.

Of predisposing factors, the level of income and education have increased among older people in the Netherlands (Galenkamp et al. 2016) and in other countries as well (Fors and Thorslund 2015; Jagger et al. 2016). This may suggest improvements in health due to the fact that low education is associated with poor health (Fors and Thorslund 2015; Hoogendijk et al. 2008, 2014; Leopold and Engelhardt 2013). Education and income can also be seen as enabling components in care use due to the fact that those who have a higher education and higher income might have better access to care (Paraponaris, Davin and Verger 2012).

With regard to the enabling factors and informal care use, the most common informal care-givers are co-resident partners and non-residing children, although the care networks can be complicated and often consist of both. Care is also provided by other informal care-givers, including kin and non-kin care-givers (Jacobs et al. 2016; Johansson, Sundström and Hassing 2003). Due to societal changes, the availability of potential informal care-givers has changed over time. Increases in the number of people surviving to old age also increases the number of people living with a partner (Agree and Glaser 2009). Thus, among older people, the younger cohorts are more likely to have a spouse than the older cohorts, and family availability has improved (Ryan et al. 2012) or at least remained at the same level (Suanet, Van Tilburg and Broese van Groenou 2013). In the Netherlands, the social network size of older people had increased between 1992 and 2012 (Swinkels et al. 2016), as had the number of non-kin relationships (Suanet, Van Tilburg and Broese van Groenou 2013), which increased the scope of people who could provide informal care. Yet, the availability of informal care is not only dependent on the existence of family members, friends or neighbours, but also on their willingness or ability to provide informal care within their life circumstances and other obligations. Due to increasing longevity, people live with disabilities and chronic conditions to an older age than before, which might pose a challenge for the spouse care-giver, especially if they also suffer from poor health (Agree and Glaser 2009). Increase in retirement age of the potential care-giver, the rise in divorce rates, smaller family sizes (Agree and Glaser 2009; Broese van Groenou and De Boer 2016) and the weakening norms of family obligations (Fingerman et al. 2012; Tsutsui, Muramatsu and Higashino 2013) all limit the possibilities to provide informal care. In addition, some of the potential care receivers are not willing to be 
dependent on their family members and are reluctant to receive informal care (Johansson, Sundström and Hassing 2003).

The trends in the need factors, i.e. the number of chronic conditions and functional limitations, varies between countries and different age cohorts but the conclusion is that the most severe disabilities have decreased while mild disability has increased (Rechel et al. 2013), as has the number of chronic conditions (Prince et al. 2015). In the Netherlands, Galenkamp et al. $(2012,2016)$ had similar findings. The number of chronic conditions and mild disabilities had increased, results supported later by Alders, Comijs and Deeg (2016), and the increase was stronger among the older old (aged 75-85) than among the younger old (aged 60-74) (Galenkamp et al. 2012). The increased prevalence of chronic conditions and functional limitations added to the increase in admissions to acute care (Galenkamp et al. 2016), but simultaneously the admissions to long-term care decreased (Alders, Comijs and Deeg 2016).

The trends in cognitive impairment are also mixed and vary between different countries and age cohorts. In the United States of America, cognitive impairment decreased between the years 1993 and 2002, but remained greater among people aged 80 or older than among the younger old. In addition, cognitive impairment was reported to be concentrated in fewer individuals with a more rapid decline (Langa et al. 2008). Also in the United Kingdom (UK), cognitive functioning improved between 1991 and 2011 in the population aged 65 or older (Jagger et al. 2016). In the Netherlands, cognitive status among people aged 65-85 improved slightly (Galenkamp et al. 2016). In Sweden, the proportion of those with cognitive problems increased among people aged 77+ (Parker, Ahacic and Thorslund 2005). Thus, there are positive trends in the prevalence of cognitive impairment at least among the younger old, yet due to the increasing longevity and ageing of the population alone, the number of people with cognitive impairment is predicted to increase within the next decades. This will cause serious implications for individuals and their families, and for demands on health and social care (Jagger et al. 2009; Van Bussel et al. 2017).

\section{Changes in care and care policy in the Netherlands}

In addition to individual determinants of care, the allocation of care can also change over time. Reforms in long-term care have been considerable over the past decades in the Netherlands. Since the 1980s, de-institutionalisation of care and expansion of homecare services was conceived as a cost-containment strategy. Since then, the use of institutional long-term care has fallen and has been compensated for by an increase in homecare use (De Meijer et al. 2015). Yet, the homecare services have not been as cost-containing as expected, and different service supply and funding strategies have been introduced in homecare during the past decades, during which the role and recognition of informal care-givers has also been widened (Da Roit 2012). A consumer-directed scheme called the 'personal budget' was introduced in 1995, which after 1997 also included family members. The care recipient could choose either regular homecare or the services from the care provider they preferred, or buy the care from a family member (Kremer 2006). In 2005, the definition of the expected care contribution of the co-resident family 
member of the chronically ill person was widened, and co-resident family members were also expected to help with the household activities. In 2007, the Social Support Act was introduced which stated that local communities should provide services and domestic care for people in need and their informal care-givers. In 20042008, a stricter eligibility criterion for access to homecare in the presence of co-resident family members was introduced (Da Roit 2012).

De-institutionalisation and the effect of policy initiatives examined in previous research found that in the last decades the use of institutional long-term care in the older Dutch population has decreased (Alders, Comijs and Deeg 2016; De Meijer et al. 2015) while formal homecare use has increased. Simultaneously, the use of informal care decreased, but there are signs that formal and informal homecare have become more complementary rather than a substitute for each other in recent years. (Swinkels et al. 2016).

As the availability of informal care-givers has mainly increased, it is possible that the use of informal care has increased over time. Care policy trends have increasingly shifted towards homecare provided by informal care-givers and formal homecare. In addition to this policy development, mixed health trends imply there are more chronic conditions and mild disability, but less severe disability, which may have increased the need for and the use of informal care and formal homecare instead of institutional care. Due to these developments, it is possible that in the group of cognitively impaired people, who are usually in higher need for care, the combination of informal care and formal care has increased, while the use of residential care has decreased.

\section{Research questions}

(1) To what extent has the use of informal care, formal homecare, community services and residential care changed between the years 1992-2012 among people aged 65-85 with cognitive impairment in the Netherlands?

(2) To what extent is the use of different types of care associated with the availability of potential informal care-givers, and has that changed during the study years?

(3) Is there an interdependency between the use of informal care, formal care and community services by cognitively impaired older people, and has that changed during the study years?

\section{Methods}

Data

This study employs the Longitudinal Aging Studies Amsterdam (LASA) data. LASA is an ongoing longitudinal study focusing on the consequences of ageing, including information on physical, cognitive, psychological and social functioning in older age, the use of care and the changes that occur over time (Hoogendijk et al. 2016). The first interviews were carried out in 1992-1993 among respondents aged 55-85 $(\mathrm{N}=3,107)$. Measurement time periods are conducted every three years. In addition to the baseline cohort, in 2002-2003 a new cohort aged 55-65 was added 
to the sample $(\mathrm{N}=1,002)$. They are included in subsequent measurements. The latest available data are from the years $2011-2012(\mathrm{~N}=1,522)$. In this study, data from all seven measurement time periods are used. The original LASA sample is based on a nationally representative sample of older adults, based in three geographic regions in the Netherlands (Huisman et al. 2011). At all measurement waves, both community-dwellers and people living in residential homes were included in the survey.

The Mini-Mental State Examination (MMSE) was employed in every data collection. MMSE is used as a screener of cognitive impairment. It includes 20 interview questions concerning different cognitive domains and the score ranges from 0 to 30 , a higher score indicating better cognitive functioning.

\section{Sample of cognitively impaired persons}

The MMSE score is strongly influenced by age and education. A lower MMSE score without cognitive impairment is associated with lower education and higher age (Feng et al. 2012; Schmand et al. 1995). We used age- and education-specific norms (Kempen, Brilman and Ormel 1995) to determine cut-off points to identify people with cognitive impairment in every cohort (age- and education-based mean MMSE score -1.5 standard deviations). According to this classification, the MMSE cut-off point had a range from 27 of those highest educated 65-69 year olds to 21 of the lowest educated 80-85 year olds. In all, the MMSE score range among those who were classified as cognitively impaired was $2-27$. In every study year around 10 per cent of the total study population were classified as cognitively impaired. Only those who had valid MMSE scores were included in the study population. To make samples of different cohorts comparable, and to keep the cohorts similar in age to the group to whom the findings will be generalised between the study years, only those who fell in the age range of 65-85 were included. In terms of the age range used in this study, it should be acknowledged that the findings represent younger old people with cognitive impairment, i.e. those aged 65-85, not the oldest old.

The proportion of those who fell into the group of cognitively impaired in consecutive study time periods was rather low: 22 per cent of those who were classified as cognitively impaired and fell into the age range of $65-85$ in the first wave were also included in the study sample in the second wave. From the second sample of cognitively impaired, 23 per cent were included in the third sample; from the third, 23 per cent in the fourth; from the fourth, 19 per cent in the fifth; from the fifth, 21 per cent in the sixth and from the sixth, 26 per cent in the last time period. More detailed examination showed that around 30 per cent also participated in the interviews in the next time period but were no longer cognitively impaired according to the age- and education-adjusted MMSE score, around 8 per cent were older than 85 and thus did not fall into the age range any more, 21 per cent had died before the next interview, 13 per cent did not participate in the next face-to-face interview but only in a telephone or proxy interview, 3 per cent refused, 2 per cent were ineligible to participate and 1 per cent were not contacted. This indicates that more than half of the respondents were included in the study sample only once. The total number of interviews in the seven time periods amounts to 1,022, gathered from 813 respondents. 


\section{Measurements}

\section{Outcome variables}

This study concentrates on five outcomes. The four care types studied were informal care, publicly provided formal homecare, community services and residential care. Two questions were asked: 'Do you receive help with personal care, for example washing, bathing, dressing?' and 'Do you receive help with domestic activities, for example cleaning, shopping, cooking?' If answered in the affirmative, the respondent was asked who provided this type of help. Informal care included personal and domestic help provided by an unpaid care-giver (partner, son or daughter, other relative, neighbour or friend). Formal care included personal and domestic help provided by a professional care-giver from a homecare organisation. Community services included the use of telephone help services, meals on wheels, open table (a type of meal service), volunteers, transport services or domestic services (help with small household tasks). Residential care is the care offered in a residential care facility round-the-clock for those who are unable to live in the community and have the most demanding care needs. The fifth outcome variable consisted of those persons who did not use any of the above-mentioned care types, or private homecare, and was therefore titled the no care group.

\section{Explanatory variables}

The year of observation is used as an explanatory variable that refers to the historical time period, created using the year of interview (Swinkels et al. 2016). Predisposing variables consist of socio-demographic factors, in this study age, gender, and educational level ranging from low (elementary school only), median (secondary education) to high (college, university or higher). The need variables include MMSE score, number of functional limitations (range $0-3$, highest score refers to highest difficulty) and number of chronic conditions out of seven major conditions. Functional limitations were measured in three areas: the ability to use stairs, to use own or public transport, or to cut own toenails. Chronic conditions included (a) lung disease, (b) cardiac disease, (c) peripheral arterial disease, (d) diabetes, (e) cerebrovascular accident, (f) osteoarthritis or rheumatoid arthritis and (g) cancer. Enabling variables included living with a partner, having a partner outside the household, living with a son or daughter, i.e. a child, at least one child living nearby (approximately 30 minutes travelling distance) and the social network size (range 0-78, higher score indicates larger network size). A sense of mastery, i.e. the feeling that one has control of events and ongoing situations (range 5-25, higher score indicates a greater sense of mastery), and private care, i.e. personal or domestic care that is paid out of pocket, are used in this study as enabling factors. The data included help provided by volunteers and other non-kin, but as their share in this sample was minor or non-existent they were not included in the analysis.

\section{Analyses}

The descriptive statistics were adjusted for age and gender, using analysis of variance in every time period so that the changes in care use between the observation years would not reflect age and gender differences in different time periods but 
rather the differences between them. For statistical analysis, generalised estimating equations (GEE) logistic regression analysis was applied using IBM Statistics 23. This method corrects within-subject correlations; GEE combines within-subject relationships with a between-subject relationship, resulting in one single regression coefficient (Galenkamp et al. 2012; Twisk 2013). An unstructured correlation matrix was used because it assumes all correlations to be different. In community services Models 3-6 the exchangeable correlation matrix was used due to better model fit. All five outcome variables were dichotomous variables $(1=$ uses the services, $0=$ does not use), measured in every time period. Time trends in care use might be non-linear, thus the year of observation is included in Models 1-4 and 6 as a continuous variable, and in Models 1 and 5 as a categorical variable, to show the yearly differences. Time-squared $\left(\right.$ year $\left.^{2}\right)$ was tested in every model yet it was statistically significant only in the interaction term formal homecare $x$ year $^{2}$ (significance level $p<0.10$ ) in community services (Table 4 ), thus we dropped the variable time-squared.

In univariate models, every explanatory variable was included separately in the model to describe the univariate association with the outcome variable before other explanatory variables were taken into account (Model 1). Next, the predisposing characteristics and health-related factors were included in Model 2. In Model 3, the enabling variables were added. When informal care, formal homecare or community services were studied, the potential interdependent types of care were included in Models 4 and 5. Different services may be complementary, or be substitutes for each other, and thus different types of care were used as explanatory variables. Residential care is offered in a care facility, thus homecare is not complementary care to residential care. In Model 6 (Model 5 in residential care), the explanatory variables of interest (i.e. potential informal care-givers and other types of care), of which significance was proven in Models 4 and $5(p<0.05)$, were studied with interaction terms with observation year to reveal the possible changes over time (interaction term significance level $p<0.10$ ). To illustrate the use of different care types in different observation years when predisposing, enabling and health-related individual characteristics are taken into account using the analysis of variance, the proportions of users are shown in Figure 1.

\section{Results}

\section{Description of the study population}

Between the study years the mean age varied from 73.4 to 76.7 years. The study population was slightly younger in later years due to selective drop-out of the older frail respondents and the addition of 55-65 year olds in 2002-2003 (Table 1). About half were female. The level of education increased during the years studied. In the early study years about a quarter had intermediate or higher education, but in later years more than half had achieved this. The mean MMSE score was slightly higher in later years. The mean number of functional limitations and the mean number of chronic conditions fluctuated but increased between the first and the last time periods, although the increase was statistically significant only in chronic conditions. 


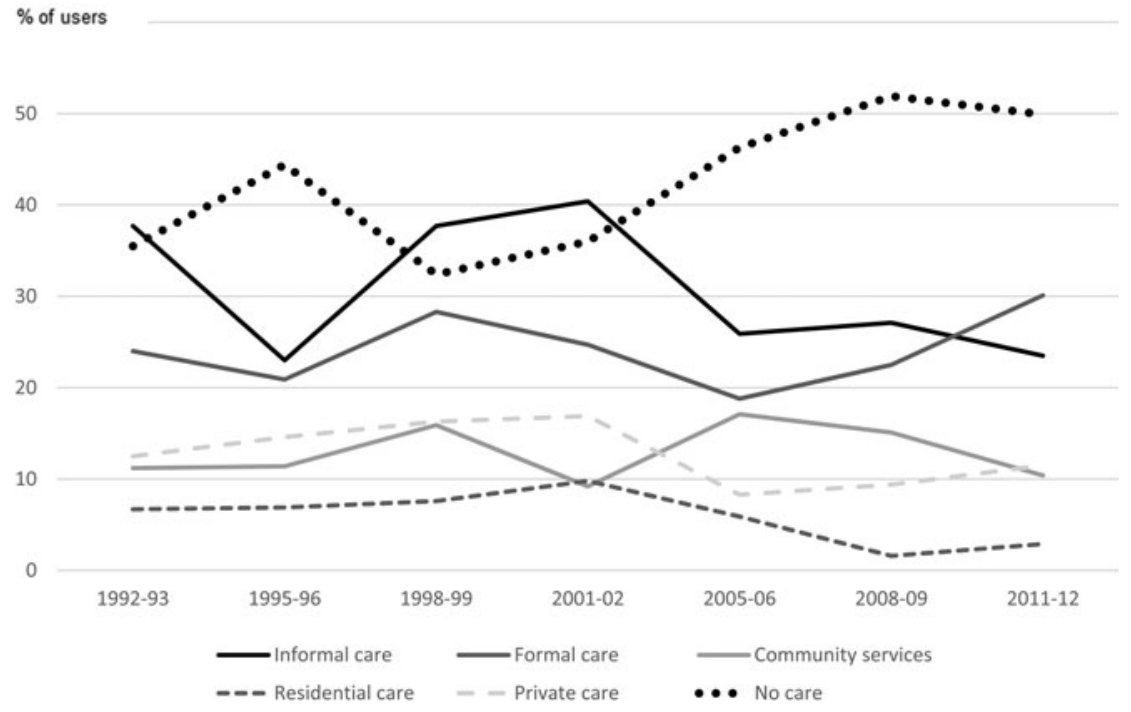

Figure 1. Proportion of care users in 1992-2012.

Note: All proportions are adjusted for the predisposing, enabling and need variables.

\section{The change in use of care between 1992 and 2012}

The proportion of users of different types of care fluctuated between the study years when age and gender were taken into account (Table 1). Between the earlier and later study years, the use of informal care and residential care decreased: in Figure 1, informal care and residential care both show decreasing trends, especially after 2001-2002. The decrease in informal care and residential care was statistically significant in univariate models (Tables 2 and 3), and in the models where all explanatory variables were taken into account when studying informal care between the reference years (1992-1993) and the years 1995-1996 and 2011-2012 (Table 2, Model 5), and residential care in Model 3 (Table 3).

When age and gender were taken into account, the use of formal homecare and community services increased, as did the proportion of those who used privately paid homecare services, but these changes were not statistically significant (Table 1). When the explanatory variables were taken into account, the proportion of community service and formal homecare users fluctuated between the study years (Figure 1). The differences in formal homecare use between the observation years were not statistically significant in any of the models (Table 4). In community services, the increase was statistically significant in the univariate model between the reference years and the years 1998-1999 and 2005-2006 (Table 5). However, the statistically significant differences were no longer present after the predisposing and health-related factors were included (Model 2).

When all of the care types were totalled, the no care group increased, especially after the late 1990s (Figure 1). The increase in the no care group was statistically significant when all of the explanatory variables were included in the models (Table 6, Models 3 and 4). 
Table 1. Description of the study sample: means and percentages of the variables in seven waves, cognitively impaired, age $65-85$ years

\begin{tabular}{|c|c|c|c|c|c|c|c|c|}
\hline & $\begin{array}{l}\text { Wave } 1 \\
\text { 1992-3 }\end{array}$ & $\begin{array}{l}\text { Wave 2, } \\
\text { 1995-6 }\end{array}$ & $\begin{array}{l}\text { Wave 3, } \\
\text { 1998-9 }\end{array}$ & $\begin{array}{l}\text { Wave 4, } \\
2001-2\end{array}$ & $\begin{array}{l}\text { Wave } 5 \text {, } \\
2005-6\end{array}$ & $\begin{array}{l}\text { Wave 6, } \\
2008-9\end{array}$ & $\begin{array}{l}\text { Wave } 7 \\
2011-12\end{array}$ & $p^{1}$ \\
\hline $\mathrm{N}$ & 285 & 199 & 142 & 110 & 112 & 91 & 83 & \\
\hline Mean age & 76.7 & 76.1 & 75.9 & 74.3 & 73.9 & 73.9 & 73.4 & $<0.001$ \\
\hline Female (\%) & 53.7 & 50.3 & 52.8 & 52.7 & 50.9 & 45.1 & 50.6 & ns \\
\hline \multicolumn{9}{|l|}{ Education: } \\
\hline Low & 73.3 & 69.3 & 67.6 & 58.2 & 51.8 & 49.5 & 39.8 & $<0.001$ \\
\hline Intermediate & 14.7 & 17.1 & 17.6 & 23.6 & 27.7 & 22.0 & 31.3 & $<0.001$ \\
\hline High & 11.9 & 13.6 & 14.8 & 14.8 & 19.6 & 23.1 & 25.3 & $<0.001$ \\
\hline Mean MMSE $^{2}$ & $20.8(20.3)$ & $20.9(20.7)$ & $20.8(20.6)$ & $20.7(21.1)$ & $21.5(22.0)$ & $21.5(22.0)$ & $22.0(22.7)$ & $<0.001$ \\
\hline $\begin{array}{l}\text { Functional limitations } \\
(\text { mean, range } 0-3)^{3}\end{array}$ & $1.2(1.3)$ & $1.4(1.4)$ & $1.5(1.5)$ & $1.4(1.3)$ & $1.4(1.3)$ & $1.3(1.2)$ & $1.3(1.2)$ & ns \\
\hline $\begin{array}{l}\text { Chronic conditions (mean, } \\
\text { range } 0-7)^{3}\end{array}$ & $1.1(1.1)$ & $1.4(1.4)$ & $1.6(1.6)$ & $1.5(1.4)$ & $1.6(1.5)$ & $1.4(1.3)$ & $1.5(1.5)$ & $<0.023$ \\
\hline \multicolumn{9}{|l|}{ Partner: ${ }^{3}$} \\
\hline In household & $55.4(52.0)$ & $48.1(47.7)$ & $48.3(47.2)$ & $52.7(54.5)$ & $52.3(55.4)$ & $54.7(59.3)$ & $56.5(60.2)$ & ns \\
\hline Outside household & $2.2(2.2)$ & $4.9(5.0)$ & $6.3(6.3)$ & $4.6(4.5)$ & $5.4(5.4)$ & $5.4(5.5)$ & $6.1(6.0)$ & ns \\
\hline Child in household & $10.1(9.7)$ & $9.9(9.5)$ & $10.9(10.6)$ & $6.2(6.6)$ & $4.4(5.2)$ & $6.1(6.5)$ & $0.7(1.6)$ & ns \\
\hline Child nearby & $57.1(56.8)$ & $64.5(64.3)$ & $63.3(63.1)$ & $65.8(65.8)$ & $61.6(61.8)$ & $67.8(68.9)$ & $53.8(54.0)$ & ns \\
\hline $\begin{array}{l}\text { Network size (mean number } \\
\text { of persons) }\end{array}$ & $11.3(11.1)$ & $13.1(12.8)$ & $13.0(12.9)$ & $13.0(13.3)$ & $13.2(13.5)$ & $12.1(12.4)$ & $12.8(13.1)$ & 0.046 \\
\hline
\end{tabular}


Table 2. Factors associated with the use of informal care (logistic regression analysis)

\begin{tabular}{|c|c|c|c|c|c|c|c|c|c|c|c|c|}
\hline & \multicolumn{2}{|c|}{$\begin{array}{l}\text { Model } 1 \text {, } \\
\text { univariate }\end{array}$} & \multicolumn{2}{|c|}{ Model 2} & \multicolumn{2}{|c|}{ Model 3} & \multicolumn{2}{|c|}{ Model 4} & \multicolumn{2}{|c|}{ Model 5} & \multicolumn{2}{|c|}{ Model 6} \\
\hline & OR & $p$ & OR & $p$ & OR & $p$ & OR & $p$ & OR & $p$ & OR & $p$ \\
\hline Year (continuous) & 0.97 & 0.003 & 0.98 & 0.12 & 0.98 & 0.10 & 0.98 & 0.12 & & & 1.01 & 0.75 \\
\hline \multicolumn{13}{|l|}{ Year (Ref. 1992-3): } \\
\hline $1995-6$ & 0.61 & 0.01 & & & & & & & 0.52 & 0.02 & & \\
\hline $1998-9$ & 0.96 & 0.84 & & & & & & & 1.02 & 0.95 & & \\
\hline $2001-2$ & 1.07 & 0.77 & & & & & & & 1.32 & 0.35 & & \\
\hline $2005-6$ & 0.51 & 0.01 & & & & & & & 0.68 & 0.22 & & \\
\hline $2008-9$ & 0.76 & 0.27 & & & & & & & 0.58 & 0.14 & & \\
\hline $2011-12$ & 0.37 & 0.001 & & & & & & & 0.51 & 0.05 & & \\
\hline Sex (Ref. Male) & 1.09 & 0.52 & 0.92 & 0.56 & 1.12 & 0.57 & 1.11 & 0.58 & 1.09 & 0.69 & 1.11 & 0.61 \\
\hline Age & 1.07 & $<0.001$ & 1.04 & 0.003 & 1.08 & $<0.001$ & 1.09 & $<0.001$ & 1.09 & 0.000 & 1.09 & $<0.001$ \\
\hline \multicolumn{13}{|l|}{ Education (Ref. Low): } \\
\hline Intermediate & 0.53 & 0.001 & 0.64 & 0.03 & 0.75 & 0.24 & 0.77 & 0.32 & 0.75 & 0.29 & 0.79 & 0.37 \\
\hline High & 0.66 & 0.04 & 0.74 & 0.18 & 0.73 & 0.32 & 0.78 & 0.43 & 0.77 & 0.42 & 0.79 & 0.46 \\
\hline MMSE & 0.94 & $<0.001$ & 1.02 & 0.48 & 1.05 & 0.22 & 1.03 & 0.38 & 1.03 & 0.50 & 1.04 & 0.31 \\
\hline Functional limitations & 1.33 & $<0.001$ & 1.21 & 0.01 & 1.19 & 0.05 & 1.26 & 0.01 & 1.26 & 0.02 & 1.32 & 0.004 \\
\hline Chronic conditions & 1.14 & 0.02 & 1.00 & 0.98 & 0.99 & 0.92 & 1.03 & 0.76 & 1.03 & 0.76 & 1.01 & 0.89 \\
\hline
\end{tabular}




\begin{tabular}{|c|c|c|c|c|c|c|c|c|c|c|c|}
\hline \multicolumn{12}{|l|}{ Partner (Ref. No partner): } \\
\hline In household & 1.44 & 0.01 & & 1.09 & 0.01 & 1.70 & 0.02 & 1.65 & 0.03 & 2.90 & 0.002 \\
\hline Outside household & 0.80 & 0.53 & & 0.80 & 0.66 & 0.85 & 0.75 & 0.84 & 0.73 & 0.84 & 0.86 \\
\hline Child in household & 2.71 & $<0.001$ & & 3.10 & $<0.001$ & 3.01 & $<0.001$ & 3.07 & 0.000 & 3.76 & 0.004 \\
\hline Child nearby & 1.18 & 0.31 & & 1.13 & 0.50 & 1.10 & 0.59 & 1.10 & 0.61 & 1.11 & 0.58 \\
\hline Network size & 1.01 & 0.51 & & 1.01 & 0.67 & 1.01 & 0.52 & 1.01 & 0.45 & 1.00 & 0.77 \\
\hline Mastery & 0.95 & 0.01 & & 0.98 & 0.49 & 0.97 & 0.23 & 0.97 & 0.32 & 0.95 & 0.39 \\
\hline Privately paid homecare & 0.82 & 0.34 & & & & 0.67 & 0.18 & 0.66 & 0.17 & 0.67 & 0.17 \\
\hline Formal homecare & 0.74 & 0.04 & & & & 0.45 & 0.003 & 0.17 & 0.003 & 0.27 & 0.001 \\
\hline Community services & 1.20 & 0.31 & & & & 1.30 & 0.39 & 1.26 & 0.47 & 1.25 & 0.46 \\
\hline \multicolumn{12}{|l|}{ Partner $\times$ year: } \\
\hline In household & & & & & & & & & & 0.93 & 0.04 \\
\hline Outside household & & & & & & & & & & 0.97 & 0.84 \\
\hline Child in household & & & & & & & & & & 0.97 & 0.61 \\
\hline Formal $\times$ year & & & & & & & & & & 1.06 & 0.10 \\
\hline $\begin{array}{l}\text { Quasi-likelihood } \\
\text { (goodness of fit) }\end{array}$ & & & $1,173.49$ & & & & & & & & \\
\hline
\end{tabular}

Notes: Binary logistic regression models with generalised estimating equations. Ref.: reference category. MMSE: Mini-Mental State Examination.

Significance levels: Statistically significant $(p<0.05)$ odds ratios (OR) are bold; for interaction terms the significance level is $p<0.10$. 
Table 3. Factors associated with the use of residential care (logistic regression analysis)

\begin{tabular}{|c|c|c|c|c|c|c|c|c|c|c|}
\hline & \multicolumn{2}{|c|}{$\begin{array}{l}\text { Model } 1 \text {, } \\
\text { univariate }\end{array}$} & \multicolumn{2}{|c|}{ Model 2} & \multicolumn{2}{|c|}{ Model 3} & \multicolumn{2}{|c|}{ Model 4} & \multicolumn{2}{|c|}{ Model 5} \\
\hline & OR & $p$ & OR & $p$ & OR & $p$ & OR & $p$ & OR & $p$ \\
\hline Year (continuous) & 0.96 & 0.01 & 0.946 & 0.01 & 0.94 & 0.05 & & & 0.88 & 0.06 \\
\hline \multicolumn{11}{|l|}{ Year (Ref. 1992-3): } \\
\hline $1995-6$ & 1.00 & 0.99 & & & & & 0.97 & 0.98 & & \\
\hline $1998-9$ & 1.16 & 0.56 & & & & & 0.88 & 0.84 & & \\
\hline $2001-2$ & 1.01 & 0.97 & & & & & 1.74 & 0.48 & & \\
\hline $2005-6$ & 0.48 & 0.07 & & & & & 0.62 & 0.61 & & \\
\hline $2008-9$ & 0.64 & 0.24 & & & & & - & - & & \\
\hline $2011-12$ & 0.17 & 0.02 & & & & & 0.14 & 0.17 & & \\
\hline Sex (Ref. Male) & 1.61 & 0.03 & 1.33 & 0.29 & 0.64 & 0.40 & 0.66 & 0.48 & 0.59 & 0.34 \\
\hline Age & 1.21 & $<0.001$ & 1.11 & $<0.001$ & 1.05 & 0.27 & 1.10 & 0.13 & 1.09 & 0.21 \\
\hline \multicolumn{11}{|l|}{ Education (Ref. Low): } \\
\hline Intermediate & 0.56 & 0.05 & 1.37 & 0.38 & 1.19 & 0.84 & 1.07 & 0.94 & 1.10 & 0.95 \\
\hline High & 0.41 & 0.02 & 1.24 & 0.65 & 2.04 & 0.29 & 2.10 & 0.33 & 1.76 & 0.43 \\
\hline MMSE & 0.83 & $<0.001$ & 0.90 & 0.001 & 0.81 & $<0.001$ & 0.98 & 0.003 & 0.80 & $<0.001$ \\
\hline Functional limitations & 2.57 & $<0.001$ & 2.13 & $<0.001$ & 2.18 & 0.001 & 2.58 & $<0.001$ & 2.38 & $<0.001$ \\
\hline Chronic conditions & 1.25 & 0.01 & 1.00 & 0.98 & 1.28 & 0.13 & 1.14 & 0.52 & 1.06 & 0.21 \\
\hline
\end{tabular}




\begin{tabular}{|c|c|c|c|c|c|c|c|c|c|}
\hline \multicolumn{10}{|l|}{ Partner (Ref. No partner): } \\
\hline In household & 0.07 & $<0.001$ & & 0.19 & 0.01 & 0.17 & 0.01 & 0.16 & 0.04 \\
\hline Outside household & 1.02 & 0.96 & & 1.86 & 0.37 & 2.58 & 0.21 & 4.09 & 0.27 \\
\hline Child in household & 0.28 & 0.19 & & 0.11 & 0.03 & 0.09 & 0.14 & 0.25 & 0.19 \\
\hline Child nearby & 0.85 & 0.58 & & 1.38 & 0.43 & 1.39 & 0.49 & 1.51 & 0.32 \\
\hline Network size & 0.84 & $<0.001$ & & 0.88 & 0.01 & 0.90 & 0.04 & 0.84 & 0.01 \\
\hline Mastery & 0.88 & $<0.001$ & & 0.81 & 0.001 & 0.91 & 0.15 & 0.85 & 0.004 \\
\hline \multicolumn{10}{|l|}{ Partner $\times$ year: } \\
\hline In household & & & & & & & & 1.04 & 0.67 \\
\hline Outside household & & & & & & & & 0.95 & 0.60 \\
\hline Child in household $\times$ year & & & & & & & & 0.84 & 0.32 \\
\hline Network $\times$ year & & & & & & & & 1.01 & 0.21 \\
\hline Quasi-likelihood (goodness of fit) & & & 535.96 & & & & & & \\
\hline
\end{tabular}

Notes: Binary logistic regression models analysed with generalised estimating equations. Ref.: reference category. MMSE: Mini-Mental State Examination. -: information not available. Significance levels: Statistically significant $(p<0.05)$ odds ratios (OR) are bold; for interaction terms the significance level is $p<0.10$. 
Table 4. Factors associated with the use of formal homecare (logistic regression analysis)

\begin{tabular}{|c|c|c|c|c|c|c|c|c|c|c|c|c|}
\hline & \multicolumn{2}{|c|}{$\begin{array}{l}\text { Model } 1 \text {, } \\
\text { univariate }\end{array}$} & \multicolumn{2}{|c|}{ Model 2} & \multicolumn{2}{|c|}{ Model 3} & \multicolumn{2}{|c|}{ Model 4} & \multicolumn{2}{|c|}{ Model 5} & \multicolumn{2}{|c|}{ Model 6} \\
\hline & OR & $p$ & OR & $p$ & OR & $p$ & OR & $p$ & OR & $p$ & OR & $p$ \\
\hline Year (continuous) & 0.93 & 0.53 & 1.02 & 0.14 & 1.03 & 0.15 & 1.02 & 0.41 & & & 1.05 & 0.22 \\
\hline \multicolumn{13}{|l|}{ Year (Ref. 1992-3): } \\
\hline $1995-6$ & 0.91 & 0.59 & & & & & & & 0.71 & 0.34 & & \\
\hline $1998-9$ & 1.31 & 0.16 & & & & & & & 1.12 & 0.79 & & \\
\hline $2001-2$ & 0.90 & 0.65 & & & & & & & 1.13 & 0.79 & & \\
\hline $2005-6$ & 0.80 & 0.37 & & & & & & & 0.74 & 0.51 & & \\
\hline $2008-9$ & 0.74 & 0.25 & & & & & & & 0.85 & 0.72 & & \\
\hline $2011-12$ & 0.99 & 0.98 & & & & & & & 1.59 & 0.29 & & \\
\hline Sex (Ref. Male) & 1.72 & $<0.001$ & 1.25 & 0.24 & 0.94 & 0.82 & 1.08 & 0.81 & 1.03 & 0.92 & 1.08 & 0.80 \\
\hline Age & 1.16 & $<0.001$ & 1.09 & $<0.001$ & 1.07 & 0.003 & 1.08 & 0.001 & 1.09 & 0.001 & 1.08 & 0.002 \\
\hline \multicolumn{13}{|l|}{ Education (Ref. Low): } \\
\hline Intermediate & 0.31 & $<0.001$ & 0.84 & 0.49 & 0.72 & 0.35 & 1.05 & 0.91 & 1.05 & 0.89 & 1.06 & 0.87 \\
\hline High & 0.47 & $<0.001$ & 0.60 & 0.09 & 0.69 & 0.36 & 0.85 & 0.75 & 0.89 & 0.81 & 0.79 & 0.66 \\
\hline MMSE & 0.83 & $<0.001$ & 0.90 & $<0.001$ & 0.90 & 0.01 & 0.89 & 0.01 & 0.89 & 0.01 & 0.89 & 0.01 \\
\hline Functional limitations & 2.58 & $<0.001$ & 1.92 & $<0.001$ & 1.78 & $<0.001$ & 1.69 & $<0.001$ & 1.70 & $<0.001$ & 1.70 & $<0.001$ \\
\hline Chronic conditions & 1.55 & $<0.001$ & 1.24 & 0.006 & 1.27 & 0.02 & 1.36 & 0.01 & 1.36 & 0.01 & 1.35 & 0.01 \\
\hline
\end{tabular}


Partner (Ref. No partner):

\begin{tabular}{|c|c|c|c|c|c|c|c|c|c|c|c|}
\hline In household & 0.27 & $<0.001$ & & 0.45 & 0.01 & 0.52 & 0.03 & 0.51 & 0.03 & 0.91 & 0.83 \\
\hline Outside household & 1.10 & 0.76 & & 1.71 & 0.25 & 1.89 & 0.18 & 1.75 & 0.25 & 4.08 & 0.15 \\
\hline Child in household & 0.26 & 0.01 & & 0.22 & 0.003 & 0.38 & 0.07 & 0.43 & 0.13 & 0.39 & 0.08 \\
\hline Child nearby & 0.96 & 0.83 & & 1.11 & 0.66 & 0.98 & 0.94 & 0.96 & 0.89 & 0.95 & 0.86 \\
\hline Network size & 0.96 & 0.002 & & 1.01 & 0.48 & 1.02 & 0.11 & 1.02 & 0.10 & 1.02 & 0.12 \\
\hline Mastery & 0.87 & $<0.001$ & & 0.91 & 0.004 & 0.88 & $<0.001$ & 0.88 & 0.001 & 0.88 & 0.001 \\
\hline $\begin{array}{l}\text { Privately paid } \\
\text { homecare }\end{array}$ & 0.29 & $<0.001$ & & & & 0.05 & $<0.001$ & 0.05 & $<0.001$ & 0.04 & 0.001 \\
\hline Informal care & 0.72 & 0.02 & & & & 0.43 & 0.003 & 0.40 & 0.001 & 0.38 & 0.04 \\
\hline Community services & 3.84 & $<0.001$ & & & & 6.92 & $<0.001$ & 7.21 & $<0.001$ & 5.43 & 0.003 \\
\hline \multicolumn{12}{|l|}{ Partner × year: } \\
\hline In household & & & & & & & & & & 0.94 & 0.11 \\
\hline Outside household & & & & & & & & & & 0.91 & 0.18 \\
\hline Private $\times$ year & & & & & & & & & & 1.03 & 0.79 \\
\hline Informal $\times$ year & & & & & & & & & & 1.02 & 0.67 \\
\hline $\begin{array}{l}\text { Community services } \times \\
\text { year }\end{array}$ & & & & & & & & & & 1.04 & 0.47 \\
\hline $\begin{array}{l}\text { Quasi-likelihood } \\
\text { (goodness of fit) }\end{array}$ & & & 889.89 & & & & & & & & \\
\hline
\end{tabular}

Notes: Binary logistic regression models analysed with generalised estimating equations. Ref.: reference category. MMSE: Mini-Mental State Examination.

Significance levels: Statistically significant $(p<0.05)$ odds ratios $(\mathrm{OR})$ are bold; for interaction terms the significance level is $p<0.10$. 
Table 5. Factors associated with the use of community services (logistic regression analysis)

\begin{tabular}{|c|c|c|c|c|c|c|c|c|c|c|c|c|}
\hline & \multicolumn{2}{|c|}{$\begin{array}{l}\text { Model } 1 \text {, } \\
\text { univariate }\end{array}$} & \multicolumn{2}{|c|}{ Model 2} & \multicolumn{2}{|c|}{ Model 3} & \multicolumn{2}{|c|}{ Model 4} & \multicolumn{2}{|c|}{ Model 5} & \multicolumn{2}{|c|}{ Model 6} \\
\hline & OR & $p$ & OR & $p$ & OR & $p$ & OR & $p$ & OR & $p$ & OR & $p$ \\
\hline Year (continuous) & 1.01 & 0.55 & 1.02 & 0.24 & 1.02 & 0.47 & 1.01 & 0.74 & & & 1.01 & 0.78 \\
\hline \multicolumn{13}{|l|}{ Year (Ref. 1992-3): } \\
\hline $1995-6$ & 1.17 & 0.59 & & & & & & & 0.99 & 0.99 & & \\
\hline $1998-9$ & 1.75 & 0.05 & & & & & & & 1.67 & 0.22 & & \\
\hline $2001-2$ & 0.89 & 0.73 & & & & & & & 0.75 & 0.60 & & \\
\hline $2005-6$ & 1.92 & 0.03 & & & & & & & 1.75 & 0.29 & & \\
\hline $2008-9$ & 1.38 & 0.35 & & & & & & & 1.41 & 0.54 & & \\
\hline $2011-12$ & 1.00 & 0.99 & & & & & & & 0.85 & 0.78 & & \\
\hline Sex (Ref. Male) & 1.17 & 0.40 & 0.99 & 0.97 & 1.71 & 0.09 & 1.79 & 0.07 & 1.84 & 0.054 & 1.78 & 0.07 \\
\hline Age & 1.09 & $<0.001$ & 1.07 & 0.002 & 1.10 & 0.01 & 1.07 & 0.09 & 1.07 & 0.097 & 1.07 & 0.09 \\
\hline \multicolumn{13}{|l|}{ Education (Ref. Low): } \\
\hline Intermediate & 0.71 & 0.19 & 0.80 & 0.43 & 1.09 & 0.82 & 1.01 & 0.99 & 0.94 & 0.82 & 0.99 & 0.97 \\
\hline High & 0.88 & 0.62 & 0.85 & 0.57 & 1.58 & 0.25 & 1.44 & 0.43 & 1.39 & 0.48 & 1.07 & 0.50 \\
\hline MMSE & 0.96 & 0.01 & 1.04 & 0.19 & 1.04 & 0.43 & 1.10 & 0.12 & 1.10 & 0.11 & 1.10 & 0.10 \\
\hline Functional limitations & 1.75 & $<0.001$ & 1.62 & $<0.001$ & 1.71 & $<0.001$ & 1.37 & 0.03 & 1.36 & 0.04 & 1.39 & 0.02 \\
\hline Chronic conditions & 1.32 & 0.001 & 0.99 & 0.86 & 1.11 & 0.41 & 1.00 & 0.98 & 0.97 & 0.82 & 0.99 & 0.94 \\
\hline
\end{tabular}




\begin{tabular}{|c|c|c|c|c|c|c|c|c|c|c|c|}
\hline In household & 0.39 & $<0.001$ & & 0.69 & 0.27 & 0.80 & 0.51 & 0.80 & 0.51 & 0.82 & 0.56 \\
\hline Outside household & 1.11 & 0.77 & & 2.96 & 0.03 & 2.43 & 0.13 & 2.29 & 0.15 & 2.44 & 0.14 \\
\hline Child in household & 0.39 & 0.15 & & 0.28 & 0.17 & 0.34 & 0.19 & 0.32 & 0.17 & 0.34 & 0.20 \\
\hline Child nearby & 1.25 & 0.34 & & 1.53 & 0.14 & 1.64 & 0.11 & 1.61 & 0.14 & 1.61 & 0.13 \\
\hline Network size & 0.97 & 0.02 & & 0.99 & 0.47 & 0.97 & 0.27 & 0.98 & 0.31 & 0.97 & 0.24 \\
\hline Mastery & 0.88 & $<0.001$ & & 0.97 & 0.42 & 1.00 & 0.96 & 0.98 & 0.77 & 1.00 & 0.95 \\
\hline Privately paid homecare & 1.58 & 0.07 & & & & 2.52 & 0.03 & 2.76 & 0.02 & 3.65 & 0.05 \\
\hline Informal care & 1.33 & 0.13 & & & & 1.54 & 0.19 & 1.52 & 0.23 & 1.54 & 0.19 \\
\hline Formal homecare & 3.95 & $<0.001$ & & & & 7.79 & $<0.001$ & 8.15 & $<0.001$ & 7.52 & 0.00 \\
\hline Private $\times$ year & & & & & & & & & & 0.95 & 0.50 \\
\hline Formal × year & & & & & & & & & & 1.01 & 0.89 \\
\hline $\begin{array}{l}\text { Quasi-likelihood } \\
\text { (goodness of fit) }\end{array}$ & & & 761.85 & & & & & & & & \\
\hline
\end{tabular}

Notes: Binary logistic regression models analysed with generalised estimating equations. Ref.: reference category. MMSE: Mini-Mental State Examination. Significance levels: Statistically significant $(p<0.05)$ odds ratios (OR) are bold; for interaction terms the significance level is $p<0.10$. 
Table 6. Factors associated with those who did not use informal care, formal homecare, community services, residential care or private homecare (logistic regression analysis)

\begin{tabular}{|c|c|c|c|c|c|c|c|c|}
\hline & \multicolumn{2}{|c|}{ Model 1 , univariate } & \multicolumn{2}{|c|}{ Model 2} & \multicolumn{2}{|c|}{ Model 3} & \multicolumn{2}{|c|}{ Model 4} \\
\hline \multicolumn{9}{|l|}{ Year (Ref. 1992-3): } \\
\hline $1995-6$ & 1.29 & 0.18 & & & 1.80 & 0.05 & & \\
\hline $2005-6$ & 2.08 & 0.001 & & & 1.89 & 0.07 & & \\
\hline $2008-9$ & 2.11 & 0.001 & & & 2.78 & 0.01 & & \\
\hline 2011-12 & 2.64 & $<0.001$ & & & 2.55 & 0.01 & & \\
\hline Sex (Ref. Male) & 0.53 & $<0.001$ & 0.560 & 0.001 & 0.60 & 0.02 & 0.58 & 0.01 \\
\hline High & 1.54 & 0.032 & 0.61 & 0.05 & 0.63 & 0.13 & 0.58 & 0.07 \\
\hline MMSE & 1.22 & $<0.001$ & 1.04 & 0.17 & 0.97 & 0.43 & 0.97 & 0.38 \\
\hline Functional limitations & 0.43 & $<0.001$ & 0.56 & $<0.001$ & 0.55 & $<0.001$ & 0.54 & $<0.001$ \\
\hline Chronic conditions & 0.68 & $<0.001$ & 0.85 & 0.04 & 0.78 & 0.02 & 0.79 & 0.01 \\
\hline
\end{tabular}




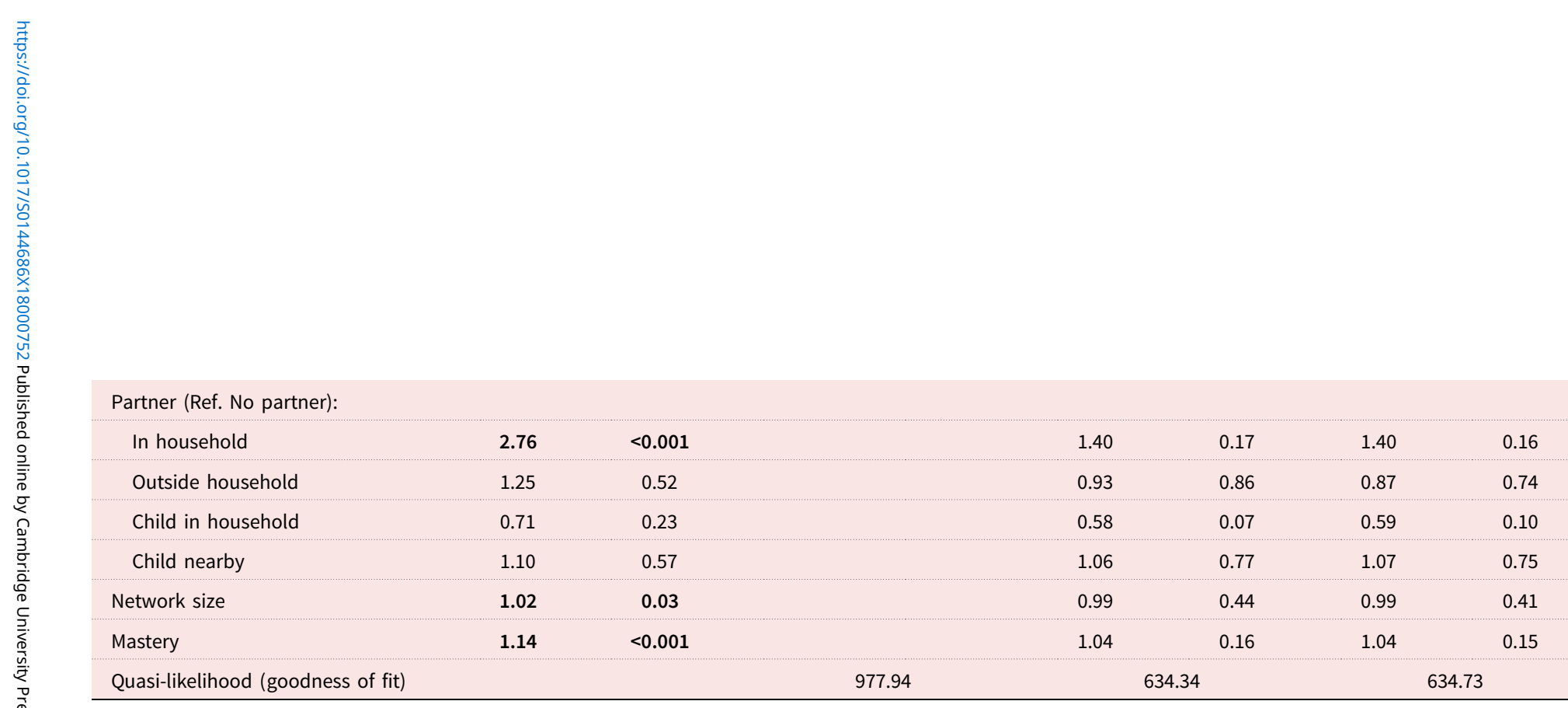

Notes: Binary logistic regression models analysed with generalised estimating equations. Ref.: reference category. MMSE: Mini-Mental State Examination. Significance level: Statistically significant $(p<0.05)$ odds ratios $(\mathrm{OR})$ are bold. 


\section{Potential informal care-givers}

The proportion of persons living with a partner decreased until 1999, after which it increased to about the same level as in 1992-1993 (Table 1). The proportion of those who had a partner outside the household increased, although the proportion was low during the whole study period. Living with a child in the same household was also relatively uncommon and decreased over time. Having a child living nearby fluctuated between the observation years but was lower in the last time period than in the first. Network size increased between the observation years and was the only element in this category that showed statistically significant changes over time.

After all explanatory variables were included in the models, the association of living with a partner increased the use of informal care and decreased the use of formal homecare and residential care. Living with a child increased the likelihood of using informal care (Table 2) and decreased the likelihood of using residential care (Table 3). A larger network size decreased the likelihood of using residential care (Table 3). After all explanatory variables were included, none of the potential informal care-givers had a significant effect on the no care group.

The interaction terms suggest that the effect of potential informal care-givers did not change over time with the exception of living with a partner on informal care (Table 2, Model 6). The association of living with a partner with informal care use diminished during the study years. More detailed examination of those living with a partner showed that among this group, informal care use increased until 2002, after which it decreased (analysis not shown).

\section{The interdependency between different types of care}

Formal homecare showed significant negative association with the use of informal care, and vice versa (Model 5 in Tables 2 and 4), which suggests they are each other's substitutes. However, the positive interaction term formal homecare $x$ year for informal care (Table 2) suggests that the complementarity between these services has increased. This means that informal care and formal homecare were increasingly used simultaneously: in more detailed examination, in 1992-1993 about a fifth but in 2011-2012 almost half of the respondents used formal care in addition to informal care (analysis not shown). The use of private care decreased the likelihood of using formal homecare, which suggests private care is a substitute for formal homecare. Community services provided complementary provision and had a positive association with the use of formal homecare and private care (Table 5). None of these associations between private care, formal homecare or community services changed over time.

\section{Other explanatory variables}

Of the health-related variables (Tables 2-6), the higher number of functional limitations increased the likelihood of the use of all four types of care, and decreased the likelihood of belonging to the no care group. Those who had lower MMSE scores were more likely to use formal homecare (Table 4, Models 4 and 5) and residential care (Table 3, Models 3 and 4) than those with higher MMSE scores. A 
higher number of chronic conditions increased the likelihood of using formal homecare (Table 4, Models 4 and 5), and decreased the likelihood of belonging to the no care group (Table 6, Models 3 and 4). Higher age increased the use of informal and formal homecare, while younger age and male gender were associated with belonging to the no care group. A higher sense of mastery decreased the likelihood of using formal homecare and residential care.

\section{Discussion}

The aims of this study were to examine to what extent has the use of informal care, public homecare services, community services and residential care changed in the course of time among people aged 65-85 with cognitive impairment. Exploring the extent to which the changes in care use are likely to reflect changes in the care system, as opposed to changes only in individual characteristics, was of special interest to us. In addition, we studied to what extent the use of different types of care is associated with the availability of potential informal care-givers, and whether there is an interdependency between the use of different care services.

The use of informal care and residential care decreased between the observation years among cognitively impaired people. The decreases were partly explained with the changes in individual characteristics such as younger average age and higher education in the later study years. However, because age and education were controlled in Models 2-6, this does not explain fully why informal care was used less in the later observation years. In residential care, the larger network size and higher MMSE score in later years explain some of the decrease over time, but not all. Use of formal homecare and community services fluctuated but did not show any clear changes between the observation years.

Use of informal care reflects the availability of potential informal care-givers, and one of the main interests of this study was to investigate the association of potential informal care-givers with the use of different types of care. Availability of informal care-givers, especially living with a partner, was important in the use of different types of care. The importance of having a co-habiting partner to the use of informal care is supported by previous studies (Bonsang 2009; Pickard 2012). Yet, even though the availability of potential informal care-givers remained at the same level between the observation years, the use of informal care decreased. In agreement with our findings, national trends in informal care seem to be fluctuating. In the Netherlands, the proportion of informal care-givers in the population aged 50 and over increased from 11.4 per cent in 2004-2006 (OECD 2011) to 16.9 per cent in 2010 (OECD 2013), but then decreased to 15.9 per cent in 2013 (OECD 2015). A similar fluctuating trend is also observed in the OECD average (OECD 2011, 2013, 2015). Eom, Penkunas and Chan (2017) found that immediate family care-givers experience lower wellbeing and higher subjective burden than non-immediate family care-givers. Also societal changes, for instance the increase in retirement age, the individualisation of lifestyles and weakening norms of family obligations may reduce the family member's possibilities to engage in an informal care relationship (Anttonen and Häikiö 2011; Fingerman et al. 2012). These effects might be even stronger if the potential care recipient is cognitively impaired, since the care-givers to people with cognitive impairment are found to face more 
problems in coping with their everyday lives than care-givers to the cognitively intact (Van Bruggen et al. 2016). Due to lack of information on informal caregivers' experiences and life situations, or the potential care receiver's willingness to receive care from a family member, our study cannot investigate the causes behind the decrease in partner contribution to informal care. In all, our findings suggest that efforts which enable informal care and support the coping mechanisms of informal care-givers would not only increase the wellbeing of the informal caregivers but would also reduce the need for formal care services (Bonsang 2009; Pickard 2012).

Decrease in residential care was an expected result due to the de-institutionalisation policy in the Netherlands (De Meijer et al. 2015), and a result supported by previous studies (Alders, Comijs and Deeg 2016; De Meijer et al. 2015). According to OECD statistics, of all-cause institutional long-term care use, the proportion of long-term care recipients has decreased during the 2000s among people aged 65-80 and among those aged 80 and over in the Netherlands (OECD 2018). In our study, a lower MMSE score was associated with the higher use of residential care, which was not a surprise since a low MMSE score is an important need factor for professional care (Vecchio et al. 2016; Zhu et al. 2013). The age- and education-adjusted average MMSE score was around 21-22 in every observation year, implying that in most cases the level of cognitive impairment varied from mild to moderate, thus they might be in 'too good a health' for residential care, especially in the later study years when the eligibility for residential care probably was stricter. This interpretation is supported by the fact that the use of residential care decreased even when we took into account the individual determinants of care use, including the health factors, in the analyses. This means that even if the health status of the respondents - MMSE score, number of functional limitations and chronic conditions - held constant over years, the use of residential care would have decreased. The trend of emphasis on those in highest need is observed also in Finland (National Institute for Health and Welfare 2016) and in the UK (Matthews et al. 2016), where long-term care residents were found to be increasingly of people with cognitive impairment and/or dementia.

Unexpectedly, the proportion of persons receiving no care at all increased over the years. This change was not explained by changes in individual characteristics and was found particularly in younger men with less functional disabilities and chronic conditions. This suggests that care services in general are offered increasingly to those in the most severe need measured by physical disability. The association of not using informal or formal care with better functional ability was also found by Paraponaris, Davin and Verger (2012). Even among those cognitively impaired, physical impairment was a more important need factor in order to be eligible for professional care services than the gravity of cognitive impairment in this group where the dominating level of cognitive impairment was mild. People with mild to moderate dementia have reported unmet needs in domains of psychological distress, company and information on available services (Kerpershoek et al. 2017; Mazurek et al. 2017; Van der Roest et al. 2009). Mazurek et al. (2017) stated that care offered to older people, also to those with cognitive problems, is more likely to meet the basic needs in the domains of accommodation, food and household 
activities than in the social and psychological areas. Our study does not provide information on the extent to which those without care use experienced unmet needs in domestic help, personal help, or in social or psychological domains, yet it would be important information in terms of the quality of life of the respondents (Mazurek et al. 2017). The factors behind the increase in those who did not use any of the care types measured in this study should be further studied: whether they manage without any help, or they lack the care they need, or the reduction in care is substituted with some other form of help, for example day care, or if living at home without any potential informal care-givers has contributed to unplanned hospitalisations (Pimouguet et al. 2016).

This study showed the interdependency between different care types and how this has changed over the years. Our results show that informal care and formal homecare could be substitutes for each other, but were also increasingly complementary services, i.e. they were used simultaneously. Substitution in formal and informal care is also found in previous studies of older adults (Bonsang 2009; Li 2005; Pickard 2012; Swinkels et al. 2016; Van Houtven and Norton 2004). The expansion of formal care decreased co-resident care, but when access to formal care decreased, use of informal care rose (Pickard 2012). However, according to Li (2005), increasing amount of formal care does not replace informal care, but rather serves as a complementary service and may provide relief to the informal care-giver's burden. This may be the situation in our study where in addition to a decrease in informal care, informal care was increasingly provided with the support from formal homecare. Privately paid care was a substitute for formal care and this association proved robust over the years. This suggests that financial resources are important in order to deal with potential further reductions in formal homecare. Of other care services studied here, the associations did not change over the years. The striking increase in those who did not use any of the care types implies that the decrease in informal care and the reduction in institutional long-term care capacity has not been substituted by other types of care.

Despite the significant findings in informal care and residential care, the results show rather modest changes between the study years. This might originate in three possible explanations: to the changes in individual determinants of care use described above, to the generosity of the Dutch care system or to the small sample size used in this study. The Dutch care system has been, and regardless of reductions still is, rather generous. In 2013, the population receiving long-term care in the Netherlands was the highest of the OEDC countries, the share of people aged 65 receiving long-term care at home was above the OECD average and the amount of funding on health-care resources was in the top five of the largest spenders of the OECD countries (OECD 2015). It is possible that the reductions in this system have not influenced the care use of cognitively impaired adults. One major limitation of this study was the small sample size of cognitively impaired people in the various time periods. The results, i.e. a decrease in informal care and in residential care and the non-significant slight increase in formal homecare, follow the same patterns found in past studies on the Dutch older population. These previous results are shown to be at least partly resulting from the changes in care policy (Alders, Comijs and Deeg 2016; De Meijer et al. 2015; Swinkels et al. 2016). With a larger sample size, it is possible that the effect of the observation years would have been stronger. 
This study has several limitations. The above-mentioned small sample size due to the fact that only those with valid MMSE scores from personal interviews could be included, might affect the statistical power of the analysis. The LASA also uses telephone interviews and proxy answers. However, for the MMSE score, a proxy answer cannot be used and the telephone interviews using the short-scale MMSE were not available for every study period, thus comparisons over time were not possible to conduct using the short-scale MMSE. Because personal participation was required, those with severe cognitive impairment, i.e. those with the highest care needs, are under-represented, as are the oldest respondents, i.e. those aged over 85 . With the constant age range over time, we are able to define to which population our findings can be generalised, that is, people with cognitive impairment aged 65-85. A similar age range in every study year is crucial to keep the samples as comparable as possible over the years. Of course, an 85-year-old in 2012 differs from an 85-year-old in 1992, with the latter possibly being more frail in many aspects, but taking differences in educational level, social resources and physical health into account enables the comparison of age groups over time. The proportion of those who were either temporarily impaired, the proportion of those who dropped out due to inability to answer the long interview in later years, or were unwilling to answer, or were deceased, is in line with the previous study investigating the course of cognitive impairment in LASA data (Comijs et al. 2004). A decline in the MMSE score might be a symptom of dementia, yet people may suffer from cognitive impairment for many reasons other than dementia, for instance depression, stress and physical diseases. Thus, it should be acknowledged that our sample includes both people with dementia and those who suffer from cognitive decline due to some other cause. A major strength is the reliable survey data, gathered from the nationally representative sample of older adults over two decades. A specific concern for studies on ageing is that attrition is considerable. However, attrition in LASA can be attributed, for the largest part, to mortality and, to a lesser extent, to refusal or other reasons (Huisman et al. 2011). In terms of explanatory variables, the LASA data include an extensive number of explanatory variables that cover health, functioning and social circumstances, which all potentially affect the need and use of care. This study adds to the previous LASA studies of care use among the older Dutch population (Alders, Comijs and Deeg 2016; Swinkels et al. 2016), with a focus solely on those who were cognitively impaired, the group that is likely to be the most vulnerable group in terms of care need. Because of the small sample size, generalisation of these results should be done with caution. However, this study provides novel information, and to our knowledge is the first study investigating the changes in the use of different types of care in the course of time among cognitively impaired people in the Netherlands.

To conclude, care policy should be prepared for the possible increase in the number of those with cognitive impairment, including dementia, and should not rely excessively on the availability of informal help, but should rather guarantee adequate formal help for those in need. This study suggests that the decrease in informal care, the reduction in the availability of formal homecare and also of residential care capacity have all contributed to the number of people aged 65-85 with cognitive impairment living at home without any care. This development is 
worrisome and future research should investigate how this group of people without informal or formal care, or residential care, cope with their everyday lives.

Acknowledgements. This work was conducted as a part of the Centre of Excellence in Research on Ageing and Care, funded by the Academy of Finland (grant number 312311). Data are from the Longitudinal Aging Study Amsterdam, which is largely funded by the Dutch Ministry of Health, Welfare and Sport. We thank the Helena Lavikainen Foundation for granting support for travel costs.

Author contributions. The corresponding author is responsible for the study design, analyses and is the main author of the manuscript. Co-authors have read the paper and are aware of its submission. M.A., M.B.G. and H.C. have made a substantial contribution to the conception and design, M.A. and J.R. to analyses and interpretation of data. All authors have contributed to the drafting of the article and have given critical comments throughout the writing process. All authors have approved the version to be published. M.A. controlled the decision to publish.

Financial support. This study is based on data from the Longitudinal Aging Study Amsterdam, which is largely funded by the Dutch Ministry of Health, Welfare and Sport. The corresponding author had a postdoctoral position in the Institute for Advanced Social Research (Research Collegium), University of Tampere, Finland. Travelling costs were funded by a travelling grant from the Helena Lavikainen Foundation.

Conflict of interest. There are no conflicts of interest.

Ethical standards. The Longitudinal Aging Study Amsterdam (LASA) has received approval by the medical ethics committee of the VU University Medical Center. Signed informed consent was obtained from all study participants. For the present study, the permission to use data was obtained from the LASA steering group using the official analysis proposal form (http://www.lasa-vu.nl/data/availability_data/availability_data.htm).

\section{References}

Agree EM and Glaser K (2009) Demography of informal caregiving. In Uhlenberg P (ed.), International Handbook of Population Ageing. Springer: Netherlands pp. 647-668. doi: 10.1007/978-1-4020-8356-3_29

Alders P, Comijs H and Deeg DJH (2016) Changes in admission to long-term care institutions in the Netherlands: comparing two cohorts over the period 1996-1999 and 2006-2009. European Journal of Ageing 14, 123-131.

Andersen R and Newman JF (1973) Societal and individual determinants of medical care utilization in the United States. The Millbank Memorial Fund Quarterly: Health and Society 51, 95-124.

Anttonen A and Häikiö L (2011) Care 'going market': Finnish elderly-care policies in transition. Nordic Journal of Social Research 2, 1-21.

Bonsang E (2009) Does informal care from children to their elderly parents substitute for formal care in Europe? Journal of Health Economics 28, 143-154.

Broese van Groenou MI and De Boer A (2016) Providing informal care in a changing society. European Journal of Ageing 13, 271-279.

Comijs HC, Dik MG, Deeg DJH and Jonker C (2004) The course of cognitive decline in older persons: results from the Longitudinal Ageing Study Amsterdam. Dementia and Geriatric Cognitive Disorders 17, $136-142$.

Connolly S, Gillespie P and O'Shea E (2014) Estimating the economic and social costs of dementia in Ireland. Dementia 13, 5-22.

Da Roit B (2012) The Netherlands: the struggle between universalism and cost containment. Health and Social Care in the Community 20, 228-237.

De Meijer C, Bakx P, Van Doorslaer E and Koopmanschap M (2015) Explaining declining rates of institutional LTC use in the Netherlands: a decomposition approach. Health Economics 24, 18-31.

Dodge HH, Kadowaki T, Hayakawa T, Yamakawa M, Sekikawa A and Ueshima H (2005) Cognitive impairment as a strong predictor of incident disability in specific ADL-IADL tasks among community-dwelling elders: the Azuchi study. Gerontologist 45, 222-230. 
Eom K, Penkunas MJ and Chan AWM (2017) Effect of caregiving relationship and formal long-term care service use on caregiver well-being. Geriatrics \& Gerontology International 17, 1714-1721.

Feng L, Chong MS, Lim WS and Ng TP (2012) The Modified Mini-Mental State Examination test: normative data for Singapore Chinese older adults and its performance in detecting early cognitive impairment. Singapore Medical Journal 53, 459-462.

Fingerman KL, Pilleman KA, Silverstein M and Suitor JJ (2012) The baby boomers' intergenerational relationships. The Gerontologist 52, 199-209.

Fors S and Thorslund $\mathbf{M}$ (2015) Enduring inequality: educational disparities in health among the oldest old in Sweden 1992-2011. International Journal of Public Health 60, 91-98.

Galenkamp H, Braam AW, Huisman M and Deeg DJH (2012) Seventeen-year time trend in poor selfrated health in older adults: changing contributions of chronic diseases and disability. European Journal of Public Health 23, 511-517.

Galenkamp H, Deeg DJH, de Jongh RT, Kardaun JW and Huisman M (2016) Trend study on the association between hospital admissions and the health of Dutch older adults (1995-2009). BMJ Open 16, e011967.

Hoogendijk E, Broese van Groenou MI, van Tilburg T and Deeg DJH (2008) Educational differences in functional limitations: comparisons of 55-65-year-olds in the Netherlands in 1992 and 2002. International Journal of Public Health 53, 281-289.

Hoogendijk EO, Deeg DJH, Poppelaars J, van der Horst M, Broese van Groenou MI, Comijs HC, Pasman HRW, van Schoor NM, Suanet B, Thomése F, van Tilburg TG, Visser $M$ and Huisman M (2016) The Longitudinal Aging Study Amsterdam: cohort update 2016 and major findings. European Journal of Epidemiology 3, 927-945.

Hoogendijk EO, van Hout HPJ, Heymans MW, van der Horst HE, Frijters DHM, Broese van Groenou MI, Deeg DJH and Huisman M (2014) Explaining the association between educational level and frailty in older adults: results from a 13-year longitudinal study in the Netherlands. Annals of Epidemiology 24, 538-544.

Huisman M, Poppelaars J, van der Horst M, Beekman AT, Brug J, van Tilburg TG and Deeg DJH (2011) Cohort profile: the Longitudinal Aging Study Amsterdam. International Journal of Epidemiology 40, 868-876.

Jacobs MT, Broese van Groenou MI, Aartsen MJ and Deeg DJ (2016) Diversity in older adults' care networks: the added value of individual beliefs and social network proximity. Journals of Gerontology: Psychological Sciences and Social Sciences 73B, 326-336.

Jagger C, Matthews R, Lindesay J, Robinson T, Croft P and Brayne C (2009) The effect of dementia trends and treatments on longevity and disability: a simulation model based on the MRC Cognitive Function and Ageing Study (MRC CFAS). Age and Ageing 38, 319-325.

Jagger C, Matthews FE, Wohland P, Fouweather T, Stephan BC, Robinson L, Arthur A, Brayne C and Medical Research Council Cognitive Function and Ageing Collaboration (2016) A comparison of health expectancies over two decades in England: results of the Cognitive Function and Ageing Study I and II. The Lancet 387, 779-786.

Johansson L, Sundström G and Hassing LB (2003) State provision down, offspring's up: the reverse substitution of old-age care in Sweden. Ageing \& Society 23, 269-280.

Kempen GI, Brilman EI and Ormel J (1995) The Mini Mental Status Examination. Normative data and a comparison of a 12 item and 20 item version in a sample survey of community-based elderly. Tijdschrift voor gerontologie en geriatrie 26, 163-172. (in Dutch)

Kerpershoek L, de Vugt M, Wolfs C, Woods B, Jelley H, Orrell M, Stephan A, Bieber A, Meyer G, Selbaek G, Handels R, Wimo A, Hopper L, Irving K, Marques M, Gonçalves-Pereira M, Portolani E, Zanetti O, Verhey F and Actifcare Consortium (2017) Needs and quality of life of people with middle-stage dementia and their family carers from the European Actifcare study. When informal care alone may not suffice. Aging and Mental Health. Published online 25 October, doi:10.1080/ 13607863.2017.1390732.

Kremer M (2006) Consumerism in charge of care: the Dutch personal budget and its impact on the market, professionals and the family. European Societies 8, 385-401.

Langa KM, Larsond EB, Karlawishe JH, Cutlerf DM, Kabetoa MU, Kimg SY and Rosen AB (2008) Trends in the prevalence and mortality of cognitive impairment in the United States: is there evidence of a compression of cognitive morbidity? Alzheimer's \& Dementia 4, 134-144. 
Leopold L and Engelhardt H (2013) Education and physical health trajectories in old age. Evidence from the Survey of Health, Ageing and Retirement in Europe (SHARE). International Journal of Public Health 58, 23-31.

Li LW (2005) Longitudinal changes in the amount of informal care among publicly paid home care recipients. The Gerontologist 45, 465-473.

Luppa M, Luck T, Brähler E, König HH and Riedel-Heller SG (2008) Prediction of institutionalisation in dementia. Dementia and Geriatric Cognitive Disorder 6, 65-78.

Luppa M, Luck T, Weyerer S, Brähler E, König HH and Riedel-Heller SG (2010) Prediction of institutionalization in the elderly. A systematic review. Age and Ageing 39, 31-8.

Matthews FE, Bennet H, Wittenberg R, Jagger C, Dening T, Brayne C and Cognitive Function Ageing Studies (CAFS) Collaboration (2016) Who lives where and does it matter? Changes in the health profiles of older people living in the long term care and the community over two decades in a high income country. PLOS ONE 11, e0161705.

Mazurek J, Szcześniak D, Urbańska K, Dröes RM and Rymaszewska J (2017) Met and unmet care needs of the elderly with dementia living at home: personal and informal carers' perspectives. Dementia. Published online 1 January, doi:10.1177/1471301217733233.

National Institute for Health and Welfare (2016) Social welfare and health services used by clients with memory disorders, 2003-2013. In Statistical Yearbook on Social Welfare and Health Care 2016, pp. 6667. Available online at http://www.julkari.fi/bitstream/handle/10024/131969/URN_ISBN_978-952-302784-8.pdf?sequence=1 (Accessed 10 May 2017).

Organisation for Economic Co-operation and Development (OECD) (2011) Health at a Glance 2011: OECD Indicators. Population Aged 50 and Over Reporting to be Informal Carers. OECD Publishing. Available online at http://dx.doi.org/10.1787/health_glance-2011-en (Accessed 11 May 2017).

Organisation for Economic Co-operation and Development (OECD) (2013) Health at a Glance 2013: OECD Indicators. Population Aged 50 and Over Reporting to be Informal Carers. OECD Publishing. Available online at http://dx.doi.org/10.1787/health_glance-2013-en (Accessed 11 May 2017).

Organisation for Economic Co-operation and Development (OECD) (2015) Health at a Glance 2015: OECD Indicators. Population Aged 50 and Over Reporting to be Informal Carers. OECD Publishing. Available online at http://www.oecd-ilibrary.org/social-issues-migration-health/health-at-a-glance2015_health_glance-2015-en (Accessed 13 March 2018).

Organisation for Economic Co-operation and Development (OECD) (2018) Long-term Care Resources and Utilisation: Long-term Care Recipients. Available online at http://stats.oecd.org/index.aspx? $r=720920$ (Accessed 8 March 2018).

Paraponaris A, Davin B and Verger P (2012) Formal and informal care for disabled elderly living in the community: an appraisal of French care composition and costs. European Journal of Health Economics 13, 327-336.

Parker MG, Ahacic K and Thorslund M (2005) Health changes among Swedish oldest old: prevalence rates from 1992 and 2002 show increasing health problems. Journals of Gerontology: Biological Sciences and Medical Sciences 60A, 1351-1355.

Pickard L (2012) Substitution between formal and informal care: a 'natural experiment' in social policy in Britain between 1985 and 2000. Ageing \& Society 32, 1147-1175.

Pimouguet C, Rizzuto D, Lagergren M, Fratiglioni L and Xu W (2016) Living alone and unplanned hospitalizations among older adults: a population-based longitudinal study. European Journal of Public Health 27, 251-256.

Plaisier I, Verbeek-Oudjik D and de Klerk M (2017) Developments in home-care use. Policy and changing community-based care use by independent community-dwelling adults in the Netherlands. Health Policy 121, 82-89.

Pot AM, Portrait F, Visser G, Puts M, Broese van Groenou MI and Deeg DJH (2009) Utilization of acute and long-term care in the last year of life: comparison with survivors in a population-based study. $B M C$ Health Services Research 9, 139.

Prince MJ, Wu F, Guo Y, Gutièrrez-Robledo LM, O'Donnel M, Sullivan R and Yusuf S (2015) The burden of disease in older people and implications for health policy and practice. The Lancet 385, 549-562.

Rechel B, Grundy E, Robine JM, Cylus J, Mackenbach JP, Knai C and McKee M (2013) Ageing in the European Union. The Lancet 381, 1312-1322. 
Ryan LH, Smith J, Antonucci TC, Jackson JS (2012) Cohort differences in the Availability of Informal Caregivers: Are the Boomers at Risk? Gerontologist 52, 177-188.

Schmand B, Lindeboom J, Hooijer C and Jonker C (1995) Relation between education and dementia: the role of test bias revisited. Journal of Neurology, Neurosurgery, and Psychiatry 59, 170-174.

Schön P, Lagergren M and Kåreholt I (2016) Rapid decrease in length of stay in institutional care for older people in Sweden between 2006 and 2012: results from a population-based study. Health and Social Care in the Community 24, 631-638.

Suanet BA, Van Tilburg TG and Broese van Groenou MI (2013) Nonkin in older adults' personal networks: more important among later cohorts? Journals of Gerontology: Psychological Sciences and Social Sciences 68B, 633-643.

Swinkels JC, Suanet B, Deeg DJH and Broese van Groenou MI (2016) Trend in the informal and formal homecare use of older adults in the Netherlands between 1992 and 2012. Ageing \& Society 36, 18701890.

Tsutsui T, Muramatsu N and Higashino S (2013) Changes in perceived filial obligation norms among coresident family caregivers in Japan. The Gerontologist 54, 797-807.

Twisk JWR (2013) Applied Longitudinal Data Analysis for Epidemiology. A Practical Guide. Second edition. New York: Cambridge University Press.

Van Bruggen S, Gussekloo J, Bode C, Touwen DP, Engberts DP and Blom JW (2016) Problems experienced by informal caregivers with older care recipients with and without cognitive impairment. Home Health Care Services Quarterly 5, 11-24.

Van Bussel EF, Richard E, Arts DL, Nooyens AC, Coloma PM, de Waal MW, van den Akker M, Biermans MC, Nielen MM, van Boven K, Smeets H, Matthews FE, Brayne C, Busschers WB, van Gool WA and Moll van Charante EP (2017) Dementia incidence trend over 1992-2014 in the Netherlands: analysis of primary care data. PLOS Medicine 14, e1002235.

Van der Roest HG, Meiland FJ, Comijs HC, Derksen E, Jansen AP, van Hout HP, Jonker C and Dröes RM (2009) What do community-dwelling people with dementia need? A survey of those who are known to care and welfare services. International Psychogeriatrics 21, 949-965.

Van Houtven CH and Norton EC (2004) Informal care and health care use of older adults. Journal of Health Economics 2, 1159-1180.

Vecchio N, Fitzgerald JA, Radford K and Fisher R (2016) The association between cognitive impairment and community service use patterns in older people living in Australia. Health and Social Care in the Community 24, 321-333.

Zhu CW, Sano M, Ferris SH, Whitehouse PJ, Patterson MB and Aisen PS (2013) Health-related resource use and costs in elderly adults with and without mild cognitive impairment. Journal of the American Geriatrics Society 61, 396-402.

Cite this article: Aaltonen M, Raitanen J, Comijs H, Broese van Groenou M (2020). Trends in the use of care among people aged 65-85 with cognitive impairment in the Netherlands. Ageing \& Society 40, 43-72. https://doi.org/10.1017/S0144686X18000752 